\title{
A COBERTURA JORNALÍSTICA NA CÂMARA DOS DEPUTADOS
}

Candyce Rocha*

Resumo: O surgimento, crescimento e a profissionalização dos veículos de comunicação da Câmara dos Deputados, com especial enfoque para o papel da Coordenação de Jornalismo, órgão criado para integrá-los e imprimir-lhes linha editorial. A importância do amadurecimento deste canal de comunicação para o cidadão comum e os desafios desta nova comunicação pública.

Palavras-Chave: Comunicação Institucional; Comunicação Pública; TV Câmara; Rádio Câmara; Agência Câmara.

\begin{abstract}
Emergence, growth and professionalization of the Chamber of Deputies' media, with special focus on the role of the Coordination of Journalism, an organization created to integrate and imprint on this media an editorial line. The importance of the maturation of this communication channel for ordinary citizens and the challenges of this new public communication.
\end{abstract}

Keywords: Public Communication; Chamber of Deputies' media; Chamber TV; Chamber Radio; Chamber News Agency.

\section{Introdução}

A Câmara dos Deputados é o palco das grandes decisões políticas que influenciam a vida de todos os cidadãos. Uma cobertura jornalística eficiente das atividades parlamentares é importante não apenas para os deputados, principais atores políticos da Casa ${ }^{1}$, mas, principalmente, para as milhares de pessoas que não têm acesso ao locus decisório e, na maioria das vezes, desconhecem os procedimentos legislativos. O aperfeiçoamento dessa cobertura também possibilita ao cidadão acompanhar e rastrear a ação dos seus representantes

\footnotetext{
* Assessora Parlamentar; Especialista em Instituições e Processos Políticos do Legislativo pelo Programa de PósGraduação do Centro de Formação, Treinamento e Aperfeiçoamento da Câmara dos Deputados e em Governo Eletrônico pelo Centro Universitário de Ciências Gerenciais - UNA. (candyce.rocha@ camara.gov.br) ${ }^{1}$ Passaremos, eventualmente, a nos referir desta forma à Câmara dos Deputados, por ser ela o âmbito
integral deste trabalho.
} 
(accountability e traceability). Não menos importante, uma cobertura jornalística eficiente deve ser perseguida também pela instituição, para que esta possa ganhar força e credibilidade junto à opinião pública e não se deixar pautar pela grande mídia, mas igualmente adquirir condições de pautá-la.

A evolução e consequente popularização dos veículos de comunicação da Câmara dos Deputados, a saber, Televisão, Rádio, Jornal e Agência Câmara, ajudam o cidadão a se familiarizar com os processos legislativos e aproximam os representados de seus representantes. Em seu livro "Imprensa e Congresso ou Como a mídia pauta a Política" (2002), a jornalista Malena Rodrigues observou a relevância da teoria do Agenda Setting (o poder de definir o que estará na pauta de discussões), oriundo da mídia externa, sobre a Câmara dos Deputados e constatou, à época da realização do estudo (1996), a quase submissão dos atores políticos ao que a mídia considerava importante. $\mathrm{Na}$ obra, a autora destaca a importância de se fazer um contrafluxo deste movimento. Para tal, o fortalecimento dos veículos de comunicação da Casa, sua profissionalização, integração e dinamização são fatores fundamentais para equilibrar esse poder de agenda.

Em outro ângulo de estudo, Nelson Rojas de Carvalho, em seu livro "E no início eram as bases - Geografia política do voto e comportamento legislativo no Brasil" (2003), mostranos a importância que a teoria da Conexão Eleitoral tem para grande parte dos parlamentares que precisam de um canal direto para prestar contas a seu eleitorado, papel esse cada vez mais preenchido pelos veículos de comunicação da instituição, mesmo com o atual crescimento das ferramentas de relacionamento direto oportunizadas pela Internet (Blogs, Twitter, Facebook, etc.).

Ressalte-se ainda que a comunicação pública de qualidade é uma demanda social pelo direito à informação. E, quando falamos em comunicação pública, é imprescindível respeitar alguns de seus fundamentos básicos, como transparência; garantia de acesso à informação; direito às informações decodificadas, ou seja, que possam ser compreendidas pelo cidadão comum; compromisso com a formação da cidadania e o bem-estar da vida em coletividade; além da formação de um receptor ativo, um cidadão partícipe do processo. Em seu livro La Communication Publique, Pierre Zémor (1995) ressalta a necessidade de se preencher esse papel:

O desenvolvimento da comunicação, notadamente a do serviço público, é uma resposta à complexidade crescente de nossas sociedades; ela facilita a busca do interesse geral que resulta de uma arbitragem difícil entre interesses singulares e categorias. A Comunicação Pública responde a uma busca da significação, bem como a uma necessidade de relação (Zémor, 1995, p. 1).

Buscando auxílio nesses estudos, entre outras fontes, este artigo recupera o contexto histórico da criação da Secretaria de Comunicação Social (Secom) da Câmara dos Deputados e seus veículos de comunicação; destaca o papel da Coordenação de Jornalismo, órgão criado em 
2003, com a missão de integrar a cobertura do sistema de notícias da Câmara; revela a percepção de eficiência dos parlamentares quanto à cobertura realizada; e discute caminhos e missões do jornalismo na Câmara.

\section{O surgimento da SECOM e seus veículos}

A Secretaria de Comunicação Social da Câmara dos Deputados foi criada em 1998, pelo Ato da Mesa $\mathrm{n}^{\circ}$ 96, que apenas determinou a troca de nomenclatura da antiga Assessoria de Divulgação e Relações Públicas (Adirp), considerada "superada". O documento explicita ainda que "a aplicação deste Ato não gera qualquer despesa ao orçamento da Câmara dos Deputados, pois somente altera as denominações dos órgãos envolvidos e, consequentemente, das funções comissionadas vinculadas". (Ato da Mesa n ${ }^{\circ}$ 96, de 19/06/1998, grifo nosso.)

Oriunda da Resolução n ${ }^{\circ}$ 20, de 1971, a Adirp, por sua vez, tinha como competência “informar e esclarecer a opinião pública a respeito das atividades da Câmara dos Deputados, utilizando, para isso, os veículos de divulgação e as técnicas de Relações Públicas, e assessorar o Presidente em questões de cerimonial.”. Com o objetivo de cumprir este papel, em 1998 foram criadas também a Rádio e a TV Câmara e foi reestruturado o Serviço Fotográfico (Sefot).

Um ano mais tarde (1999), foi criado o Jornal da Câmara, em substituição ao boletim informativo. E, por fim, em 2000, é criada a Agência de Notícias pela Internet, completando, assim, o grupo de veículos de comunicação existente hoje na Câmara dos Deputados. Em menos de uma década (1998 a 2007), a Secom expandiu sua estrutura organizacional e de pessoal (até 2007, a Secretaria possuía cerca de 500 funcionários entre o quadro fixo e terceirizado), criou quatro veículos de comunicação e hoje ganha cada vez mais espaço tanto junto, quanto frente ao jornalismo produzido pela chamada grande imprensa.

Apesar da evolução, agir como um órgão coeso e consciente de um papel a cumprir foi uma ação que ganhou força somente a partir de 2003, quando a Secom, influenciada inclusive pelos ares de mudança que tomavam conta do País com a eleição presidencial, repensa sua estrutura organizacional e sua missão enquanto agente de comunicação pública. É assim que a Secretaria realiza o I Seminário Secom, com o objetivo de discutir o seu papel dentro da instituição.

Entre as decisões resultantes deste encontro, destacamos a criação do primeiro Manual de Redação da Secom - balizador de normas (condutas e formas de escrever), que levasse em conta as especificidades da atuação na Câmara dos Deputados; e a reestruturação da Secretaria, começando pela realização de concursos para as três áreas de comunicação: TV, rádio e escrita. No texto de abertura do Manual, Márcio Araújo ressalta o papel da comunicação da Câmara dos Deputados: 
válidos para toda a imprensa com a especificidade institucional dos órgãos de comunicação da Câmara. Isso significa que o Manual deve indicar os caminhos do equilíbrio entre o critério jornalístico e o critério político, assegurando eqüidade na cobertura da atuação dos Deputados". (Câmara dos Deputados, 2003, p. 5, grifo nosso.)

No Manual, são estabelecidas as competências da Secom que, já em 2003, vivia uma realidade completamente diferente da de 1998, quando de sua criação:

No plano da comunicação em geral, compete à Secom contribuir para dar transparência ao trabalho legislativo da Câmara dos Deputados, informando a população sobre o que se passa na Casa. É, portanto, instrumento essencial para que:

1. Haja maior correspondência entre a imagem pública da Câmara e a realidade da atividade legislativa, sem as distorções derivadas de posições estereotipadas e preconceituosas;

2. Ao divulgar antecipadamente as atividades legislativas, contribuir para que os diversos segmentos organizados da sociedade brasileira possam participar ativamente das decisões tomadas pelos senhores parlamentares, reforçando dessa forma o caráter democrático da tramitação das proposições pela Câmara; (Câmara dos Deputados, 2003, p.11)

Especificamente para a área jornalística, o Manual destaca ainda duas missões básicas:

1. Dar divulgação aos trabalhos legislativos da Câmara dos Deputados, especialmente aqueles relativos às atividades das comissões técnicas, que recebem escassa cobertura da mídia em geral, não obstante sejam uma das instâncias mais importantes de produção da Casa;

2. Ser fonte de informação institucional da Câmara. (Câmara dos Deputados, 2003, p.12)

Foi neste clima de busca por coesão e por maior transparência e correspondência às atividades legislativas que, em 2003, surgiu a Coordenação de Jornalismo, órgão criado com a missão de articular, integrar e gerir as atividades de cobertura jornalística na Câmara dos Deputados.

\section{A Coordenação de Jornalismo}

O cargo de Coordenador de Jornalismo foi criado pelo Ato da Mesa $n^{\circ}$ 05, de 27/02/2003, com a atribuição de "auxiliar o Diretor da Secom no planejamento da pauta semanal do sistema de notícias da Câmara dos Deputados; coordenar a pauta diária junto às demais Coordenações da Secretaria e acompanhar sua execução". A necessidade de criação de um órgão que pudesse integrar os veículos já era uma demanda latente, principalmente, após a criação da Agência Câmara (2000). 
Em 2002, a jornalista Patrícia Roedel ganhou o terceiro lugar no concurso Câmara em Ideias $^{2}$, apresentando a proposta de criação de uma central de reportagem, vinculada à Secom, que pudesse exercer o papel de articulador dos veículos. Em 2003, a ideia foi posta em prática pelo então diretor da Secretaria, Márcio Araújo. Em entrevista concedida à autora, realizada no final de 2006, Araújo explica que as principais motivações para a criação da Coordenação de Jornalismo foram: 1- o fato de cada veículo fazer sua própria pauta e a cobertura das notícias de forma desintegrada, não existindo uma orientação editorial que norteasse a todos; 2- cada veículo estabelecer relação direta (muitas vezes personalizada) com os parlamentares; 3- um mesmo assunto, não raro, trazer abordagens conflitantes por dois ou mais veículos.

Mesmo fruto de uma demanda existente, a criação de um cargo de coordenação das atividades jornalísticas dos veículos sofreu resistência inicial por parte dos interlocutores responsáveis, que agora teriam uma nova instância para interagir e, de certa forma, prestar contas. Contudo, a Coordenação não foi pensada para estar hierarquicamente acima dos veículos, mas para ser um órgão de fomento, articulador do trabalho de cobertura jornalística por eles executado.

Dessa forma, a Coordenação passou a desenvolver uma série de produtos que ajudou a dar dinâmica e orientação ao jornalismo desenvolvido pela televisão, rádio, jornal e agência, além do Serviço Fotográfico (Sefot). Ao todo, foram criados oito produtos (Agenda da Semana, Mapas de Reportagem, Mapas de Flashes, Destaques da Mídia, Subsídios, Resultado de Reuniões/comissões, Banco de Dados e Banco de Fontes), além de uma série de serviços que vão desde as reuniões semanais de pauta até o atendimento a parlamentares e suas assessorias, ou a interlocução com a presidência da Casa.

De fato, pode-se dizer que a Coordenação de Jornalismo funciona em ritmo similar ao de uma equipe de produção de qualquer veículo de imprensa. Ajuda a definir e confirma pautas, organiza a escalação de equipes, subsidia repórteres com as informações necessárias e monitora as coberturas. Apesar de dar o tom das prioridades, tudo é "negociado" com os veículos. A definição de pautas obedece aos critérios de relevância e abrangência, o impacto que determinado assunto terá na vida das pessoas.

O que seria um cargo de assessoramento (o Coordenador de Jornalismo) cresceu e ampliou suas funções. O coordenador virou, mesmo que sem previsão regimental, uma Coordenação de Jornalismo, atualmente (setembro, 2009), mantida com uma equipe de oito pessoas (uma coordenadora-adjunta, três produtoras e quatro estagiários). Suas principais funções passaram a ser: operacional — mobilização, integração e elaboração dos produtos; e estratégica — harmonização da linha editorial e otimização dos recursos disponíveis (inclusive

\footnotetext{
${ }^{2}$ Iniciativa que integra o programa 'Mentes-em-Obra', contemplado na política de pessoal da Câmara, premiando funcionários, autores de idéias que possam trazer propostas inovadoras para a melhoria dos serviços da Casa ou como solução de problemas de gestão.
} 
humanos) para conseguir a cobertura mais ampla possível. Pela quantidade e variedade de atividades que acontecem, muitas vezes simultaneamente, durante a semana legislativa, essa organização é fundamental para garantir eficiência, otimização e abrangência nas coberturas das atividades do Poder Legislativo. Hoje, é consenso que é impossível realizar uma cobertura integral de tudo o que acontece na semana parlamentar, que tem seu ápice às terças e quartasfeiras, já que a quantidade de eventos chega a uma média de 45 a 50 pautas/dia. Além destas funções, a Coordenação por vezes faz o papel de "ouvidor", recebendo críticas e sugestões dos veículos para a melhoria do trabalho.

\section{Percepção de eficiência}

Pesquisa realizada em 2006, via e-mail, com os 513 parlamentares, procurou descobrir o nível de satisfação quanto ao trabalho de cobertura jornalística realizado pelos veículos de comunicação da Câmara dos Deputados. Na ocasião, assegurando sigilo da fonte, solicitamos que os deputados e deputadas federais respondessem a seguinte pergunta: "Em sua opinião, o trabalho de cobertura jornalística das atividades parlamentares (a cargo da Coordenação de Jornalismo) realizado na Câmara dos Deputados é: eficiente ou ineficiente? Justifique sua resposta". Apenas 40 parlamentares responderam ao questionamento, o que representa 7,79\% do total. Antes da avaliação do resultado, gostaria de analisar o baixo retorno de respostas obtidas.

A consulta foi feita no final de setembro, portanto, antes do primeiro turno das eleições de 2006. A Casa já vivia uma baixa de frequência parlamentar. Ainda assim, temíamos que, após as eleições, os resultados pudessem ser ainda menores ou mesmo afetados pelo impacto da derrota ou vitória eleitoral. Por não haver tempo a perder, optamos pela realização da consulta por meio eletrônico. Dos 40 registros, $32(80 \%)$ consideraram a cobertura jornalística das atividades parlamentares eficiente, contra seis (15\%) que a consideraram ineficiente.

Tivemos ainda dois parlamentares que fizeram considerações, mas não classificaram suas respostas nem como eficiente ou ineficiente. Os comentários desses parlamentares foram os seguintes:

1- "Razoável";

2- "Não tenho dúvidas sobre a eficiência, no sentido de sua amplitude. Porém, precisa melhorar a eficiência no sentido dos temas (mérito). Às vezes o (a) responsável pela cobertura não conhece a matéria".

Além dos registros já descritos acima, outros nove parlamentares justificaram suas respostas ou fizeram comentários. Seguem abaixo as justificativas e comentários:

\section{Eficiente}

- "Tem demonstrado imparcialidade política e bastante informativa";

- "Presença e formulação correta"; 
- "Como Relator de uma CPMI, pude verificar o acompanhamento competente de todas as atividades, valendo-me mesmo, dos próprios dados produzidos pelos jornalistas";

- "É eficiente porque atende perfeitamente à divulgação das atividades parlamentares, concedendo-nos espaço nos meios da Casa";

- "As principais atividades realizadas são divulgadas e há uma participação democrática de parlamentares em entrevistas ou programas da grade fixa da rádio e TV Câmara.";

- "A coordenação de jornalismo consegue cobrir a atividade dos 513 parlamentares de forma equilibrada e profissional".

Ineficiente

- "O jornal da Câmara reforça as notícias já discutidas e apresentadas nos jornais televisivos. Há muitos projetos de relevância e discussões menos polêmicas nas Comissões que poderiam ter destaque a partir do Jornal impresso."

Outros comentários

- "Eficientíssimo";

- "Só lamento que a Rádio Câmara, a TV Câmara e o Jornal da Câmara tenham público ouvinte, espectador e leitor tão restritos".

Apesar do índice pequeno de retorno e menor ainda de justificativas, supomos que não seria demasiado afirmar que a maioria dos parlamentares reconhece e valoriza o trabalho dos veículos de comunicação da Casa e que o retorno de $80 \%$ de apreciação positiva (dentro do universo de respostas) é uma tendência possível de generalização. Prova disso foi o investimento nas novas instalações da TV Câmara (inauguradas em 2006), que custaram mais de dois milhões de reais $(\mathrm{R} \$ 2.294 .727,06)$ e não seriam possíveis sem a anuência dos deputados.

Contudo, e potencialmente em período eleitoral, as atenções dos parlamentares estão voltadas para a mídia dos respectivos estados. Neste sentido, ressaltamos ainda a fragilidade do alcance dos veículos de comunicação da Câmara dos Deputados e mesmo da falta de pesquisas de audiência que tornem possível a mensuração deste alcance, como empecilho para uma maior valorização desses canais.

\section{Conclusão}

De imediato, duas conclusões podem ser facilmente identificadas como resultado desta pesquisa. A primeira, diz respeito à evolução evidente dos veículos de comunicação da Câmara dos Deputados: desde a criação da Secretaria de Comunicação, em 1998, até o surgimento da Agência, último veículo da Casa a ser criado (2000), a comunicação feita pelos veículos vem 
evoluindo a passos largos. Esta evolução, em nosso entendimento, se dá não apenas no aperfeiçoamento das tecnologias disponíveis, mas - e tão importante quanto - na consciência de um papel a ser cumprido enquanto agentes de comunicação pública.

Por evolução, entendo o que Pierre Zémor (1995) aponta como requisitos fundamentais para o bom exercício da comunicação no espaço público: a garantia da transparência e do acesso à informação; o uso de linguagem decodificada, de modo a torná-la acessível ao público ao qual se destina; o uso da informação enquanto instrumento de promoção da cidadania; além, é claro, de uma cobertura eficiente em conteúdo e abrangência de atividades.

Prova deste reconhecimento não se dá apenas pela percepção de eficiência dos próprios parlamentares, mas por importantes premiações que a TV, a Radio e a Agência Câmara tem recebido ao longo dos últimos anos ${ }^{3}$. Ainda sob a ótica da evolução do trabalho, também é possível identificar na instituição o surgimento de uma cultura de procedimentos que tornaram os veículos menos suscetíveis a humores e vontades políticas.

A segunda conclusão destaca a importância da criação da Coordenação de Jornalismo enquanto agente propulsor e, arriscamos a dizer, ponto de mutação deste desenvolvimento. Muito do crédito e da maturidade do trabalho hoje realizado se deve a ela. Além de ter ajudado a integrar os veículos e a criar uma linha editorial que passou a nortear os trabalhos, também dificultou que diretores e/ou responsáveis diretos pela TV, Rádio, Jornal ou Agência Câmara agissem de forma independente, o que poderia dar margem a clientelismos e relações pessoais com os parlamentares.

Vale ressaltar que o papel da Coordenação, quando submetido à correlação de forças políticas dos diretores dos veículos e do próprio diretor da Secom, pode oscilar de gestão para gestão, até pelo fato da estrutura não estar formalizada regimentalmente. Novamente, de direito, a Coordenação de Jornalismo possui apenas a previsão do cargo do Coordenador e Coordenador-Adjunto. Mas é certo também, que o espaço de trabalho por ela conquistado está legitimado. Seja enquanto orientador de políticas (caso a gestão seja mais forte e assim a favoreça), ou como um grande produtor e organizador do trabalho dos veículos. Afinal, a Coordenação trabalha para os veículos e não o contrário.

Apesar dos avanços já comprovadamente conquistados, ainda existem falhas importantes que precisam ser corrigidas. Neste sentido, a principal deficiência ainda está no parco conhecimento do público alcançado pelos veículos e na melhoria da interação com eles. Mesmo fazendo um trabalho que tem sido considerado positivo, pouco se sabe sobre para

\footnotetext{
${ }^{3}$ Em 2004, a TV Câmara recebeu o Prêmio Jornalístico Vladimir Herzog de Anistia e Direitos Humanos, na categoria documentário, com o trabalho "Florestan Fernandes, o Mestre". Em 2005, pelo quarto ano consecutivo, o site da Câmara dos Deputados ficou entre os 10 melhores sites de política do Prêmio Ibest para a Internet brasileira. Também em 2005, A Rádio Câmara e TV Câmara receberam, do Fundo das Nações Unidas para a Infância (Unicef), um certificado de reconhecimento pela participação e contribuição em projetos sociais em prol das crianças e adolescentes.
} 
quantos e para quem os veículos da Casa estão falando, uma vez que não existem registros de pesquisas a esse respeito.

O processo de crescimento e evolução da comunicação produzida em uma instituição de grande porte e deste nível de importância social, como é o caso da Câmara dos Deputados, é um caminho sem volta. Afinal, relembrando Zémor, a comunicação pública é uma demanda da sociedade (1995). Mais recentemente (outubro, 2009), a inauguração de mais um instrumento de participação e controle, a WebCâmara, que transmitirá ao vivo, pela internet, o trabalho das 22 comissões da Casa, ratifica este compromisso de transparência e de aproximação com o cidadão.

Ainda não podemos dizer aonde a evolução dos veículos de comunicação pública da Câmara dos Deputados irá nos levar, mas esperamos que contribuam para trazer o processo legislativo cada vez mais perto do cidadão da forma mais isenta possível. Entre outros objetivos desejáveis, é importante que o cidadão consiga separar o Poder Legislativo do que acontece em um determinado momento político, com determinados atores políticos. Novamente, lembrando o que diz a teoria do agendamento, quanto mais informações o indivíduo tem, menos influenciável ele fica.

\section{Referência}

BOBBIO, Norberto et al. Dicionário de política. Brasília, Editora Universidade de Brasília, 1983, vol.1-2.

BRASIL. Câmara dos Deputados. Sítio institucional. Disponível em www.camara.gov.br. Acesso em 12 nov. 09.

BRASIL. Congresso. Câmara dos Deputados. Ato da Mesa no 96, de 19/06/1998. Disponível em http://www2.camara.gov.br/legislacao/pesquisa.html

BRASIL. Congresso. Câmara dos Deputados. Ato da Mesa No. 05, de 27/02/2003. Disponível em http://www2.camara.gov.br/legislacao/pesquisa.html .

BRASIL. Congresso. Câmara dos Deputados. Regimento Interno da Câmara dos Deputados. Brasília: Câmara dos Deputados, Coordenação de Publicações, 2006. 395p.

BRASIL. Congresso. Câmara dos Deputados. Resolução da Câmara dos Deputados no 20, de 1971. Disponível em http://www2.camara.gov.br/legislacao/pesquisa.html .

CARVALHO, Nelson R. E no início eram as bases - Geografia política do voto e comportamento legislativo no Brasil. Rio de Janeiro: Renavan, 2003.

MALAVAZI, Ademir (Org). Manual de Redação da Secretaria de Comunicação Social da Câmara dos Deputados. Brasília: Câmara dos Deputados, Secretaria de Comunicação Social, 2003. 259p.

RODRIGUES, Malena R. Imprensa e Congresso ou Como a mídia pauta a Política. Brasília: Centro de Documentação e Informação - CEDI, 2002.

ZÉMOR, Pierre. La Comunication Publique. PUF, col. Que Sais-je? Paris, 1995. Tradução resumida do livro: Prof. Dra. Elizabeth Brandão. Disponível em http://www.ucb.br/comsocial/mba/ComunicacaoPublicaPierreZemor_traducao.pdf. Acesso em novembro de 2004. 